\title{
Configurationality and Mental Grammars: Sentences in Sinhala with Re- Duplicated Expressions
}

\author{
Prabath $\mathrm{KB}^{1}$ and Lalith Ananda $\mathrm{MG}^{2}$ \\ ${ }^{1}$ Ritsumeikan University, Japan \\ ${ }^{2}$ University of Sri Jayewardenepura, Sri Lanka
}

\begin{abstract}
Studies on Sinhala language (Indo-Aryan (SOV), spoken in Sri Lanka by the majority Sinhalese) concerning word order have posited different arguments where some researchers concluded that Sinhala is a nonconfigurational language, while some others argue for its configurational structure. The arguments for nonconfiguraionality can be attributed to the scrambling effects (free word-order possibility) in Sinhala which shows different ordering of constituents without affecting grammaticality. However, due to different semanticpragmatic inferences provided by differently ordered sentences, Sinhala language may possess a configurational structure despite the surface manifestation of the free-word-order phenomenon. Using the nature of scrambling effects, this experimental study examined whether sentences in the canonical word order containing re-duplicated expressions could be processed faster than those with different word orders, and therefore to what extent such orders form an integral part of one's mental grammar, the I-language. The sample consisted of 20 native speakers of Sinhala and the data consisted of 60 Sinhala sentences with such reduplicated expressions. The presentation of the stimulus was controlled by a computer program DMDX (version 5.1.0.0). Both "yes" responses, and "no" responses were presented in randomly in the centre of the computer screen $600 \mathrm{~ms}$ after the appearance of a line of asterisks '******' at the eye fixation point on the screen. The analysis confirmed that the reaction times were incongruent between different word orders: Subject-Object-Verb ordered (SOV/canonical) sentences were processed faster. Therefore, this study concluded that Sinhala sentences consisting of reduplicated expressions possess a configurational syntactic structure in terms of speed of processing and thus form part of one's mental grammar whereas non-canonical word orders are the result of conscious syntactic transformations.
\end{abstract}

KEYWORDS: Configurationality, scrambling, mental grammar

Corresponding author: M. G. Lalith Ananda, Email: mlalithananda@gmail.com 


\section{INTRODUCTION}

\subsection{Scrambling and Free Word Order}

Scrambling is a term employed in the literature for a phenomenon called free word order which is quite common in many languages of the world, including Japanese, Hindi, Russian and Persian. Ross (1967), who coined the term, had considered scrambling an optional stylistic operation, thus locating it in a separate stylistic component of the grammar rather than in the narrow syntax. This view was adopted later by other linguists as well (Chomsky, 1977).

In the early stages of research in the area of free word order and scrambling, there were two major approaches to this phenomenon: some authors considered it the result of basegeneration, and others viewed it as a syntactic operation.

From a base-generation point of view, languages are divided into two types: those with a flat structure, and thus non-configurational (Hale, 1980 and Farmer, 1980 for Japanese; Haider, 1988 for German; Mohanan, 1990 for Hindi and Urdu; É. Kiss, 1994 for Hungarian; among others), and those with a structural hierarchy, and thus configurational (Bošković, 2004; Bošković \& Takahashi, 1998; Saito \& Hoji 1983, and Saito, 1985 for Japanese; Bayer \& Kornfilt, 1994 for German; and Neeleman, 1994 for Dutch; among others).

The present study examined the free word-order phenomenon in Sinhala in order to find out whether sentences in the canonical word order containing re-duplicated expressions could be processed faster than those with different word orders, and therefore to what extent such orders form an integral part of one's mental grammar, the I-language (Chomsky, 1986).

\subsection{Objectives of the Study}

The main task of this research was to find out whether sentences consisting of reduplicated (i.e., onomatopoeic) expressions also possess a configurational (hierarchical) syntactic structure. Since different sentence types (for example, sentences consisting of adverbs, proverbs, adjectives, reduplicated expressions) can be reflected with the free-word-order phenomenon due to the differences in the information flow, it is important to examine whether all Sinhala sentence types possess a configurational structure or not. Even though some previous studies have proposed a configurational structure for Sinhala (Hettiarachchi, 2015; Kariyakarawana, 1998), the status of the reduplicated expressions in Sinhala hitherto remain unexplored. Therefore, this study focused on sentences consisting of reduplicated expressions in different word orders.

\subsection{Research Problem and the Hypotheses}

This study attempted to investigate the free word-order phenomenon in Sinhala in terms of language processing by using some reduplicated expressions in different word orders. The research problem dealt with is "what is the correlation between configurationality and language processing as part of one's mental grammars?"

The hypothesis adopted is that, a sentence in the canonical word order is processed faster than a sentence in a scrambled order because the canonical word order reflects one's mental grammar (the I-language) whereas the noncanonical orders are the syntactic result of a conscious effort. Since a native speaker of a language is not making any conscious effort in the production or perception of language, what should adhere to this principle is the canonical word order sentence rather than otherwise.

Accordingly, it is argued, any claim for configurationality or otherwise should consider the processing speed of an utterance and should not depend only on binding facts, quantifier scope, and similar syntactic diagnostics generally adopted in testing configurationality. 


\section{BACKGROUND}

\subsection{The I-language}

The I-language approach to linguistics studies individual mental grammars, entities that are internal to each person. In the terminology adopted by Chomsky (1986), when we study the grammatical competence of a native speaker of a language we are studying a cognitive system internalised within the brain/mind of such a native speaker. The ultimate goal in studying competence is to characterise the nature of the internalised linguistic system or I-language which makes native speakers proficient in that particular language.

Hence, an I-language is a system of rules, a computational system that is encoded in, or a property of, an individual brain. The study of the shared properties of all I-languages is the study of human language faculty, which is also called Universal Grammar (UG) which aims at discovering the core properties common to all Ilanguages (Chomsky, 1986).

\subsection{Sinhala Language and the Free-Word- Order Phenomenon}

Gair (1983) states that colloquial Sinhala allows discontinuous constituents. The following examples show how parts of noun phrases (NPs) can be separated from their head. In (1) the relative clause [ee pare yana] (going on that road) which modifies the head noun [bus] has been separated and moved to the sentence final position.

1. bas pare yanə]

Bus (pl) good Neg [that road (Loc) go (VAdj)

'Buses that go on that road are not good'

Discontinuous constituents are one of the characteristics of non-configurational languages, along with the absence of pleonastic subjects, a rich case system, and pro-dropping (Hale, 1983).
Heenadeerage (2002) too analyses Sinhala as a non-configurational language following the definition of non-configurationality given in Lexical Functional Grammar (LFG) (Bresnan, 2001). This is based on the identification of grammatical functions, which is structural position based in configurational languages, and this is done by other means such case marking, verb agreement and other features in nonconfigurational languages. Accordingly, nonconfigurational languages are those without fixed argument positions, and those in which the word order can be free.

Inman (1993), while acknowledging SOV as the unmarked word order in Sinhala, also generalizes that Sinhala is a free-word order language. He observes that the marked word orders are associated with various discoursepragmatic effects such as topicalization (2).

2.

a. SOV

Lamaya Aliya-va daekka
(unmarked word order)
child Nom elephant-Acc see
(Pst)

The child saw the elephant

b. OSV

Aliya-va lamaya daekka

c. VSO

Daekka lamaya aliya-va

d. VOS

Daekka aliya-va lamaya

e. SVO

Lamaya daekka aliya-va

f. OVS

Aliya-va daekka lamaya (Inman, 1993)

Based on the above evidence, Inman argues that Sinhala lacks a verb phrase (VP). He argues that simpler linear precedence is not sufficient to 
capture certain binding asymmetries in Sinhala and therefore provides the following formulation which combines both precedence and co-argumenthood.

3. A pronoun cannot bind an NP within a co argument if the pronoun precedes that coargument (Inman, 1993).

Inman provides further evidence from quantifier scope to support the free order phenomenon in Sinhala and concludes that, since Sinhala lacks a $\mathrm{VP}$, any notion of subjecthood must be defined independently of phrase structure.

Kariyakarawana (1998) makes the claim that Sinhala has a configurational structure despite the overt different word orders possible in this language. He observes that the unmarked word order is SOV, while the scrambled orders have discourse-pragmatic effects. He argues that it is not necessarily the case that any element can be freely scrambled out despite the presence of free word order phenomenon. In particular, auxiliary verbs, sentential focus, and negative elements are among those which do not allow scrambling (4).

4. Seena-da/nevey//lu/tamai loku aliyaek (va) daekka

Seena-Q/Neg/Report/Emph big elephant (Acc) see Pst

He cites evidence from Sinhala binding facts where Condition $\mathrm{C}$ of Binding theory holds for Sinhala as co-reference between a pronoun and a C-commanding antecedent is ruled out. Further evidence to rule out any flat structure for Sinhala is provided with Weak-Cross Over, and Control. Since Sinhala language is said to possess different word orders: especially in the colloquial form, there can be six different syntactic patterns for the same sentence (Gair, 1990; Inman, 1994).

5.

a. Nangee aenduma-k mahanava SOV

Younger sister (Nom) dress-Indef (Acc) sew (Prog)
'Younger sister is sewing a dress'

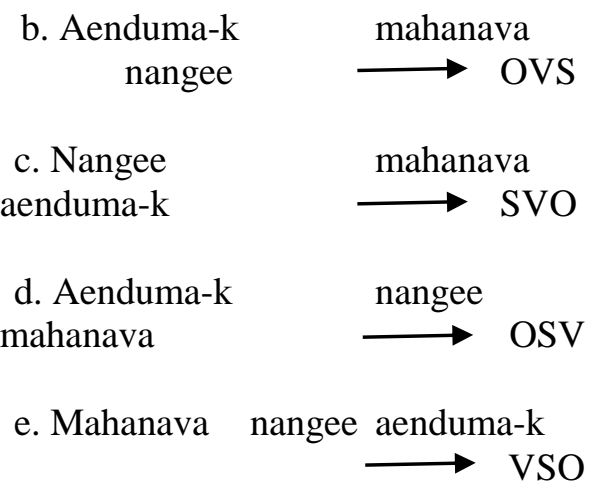

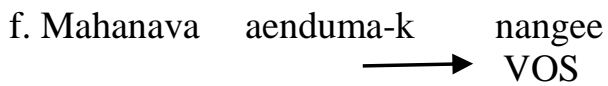

As shown in the above examples, it is evident that the word order in Sinhala language is quite flexible. As a result of this word order flexibility, Sinhala can be predicted to have a nonconfigurational syntactic structure [initially proposed by Farmer, (1984) and Hale, (1980)] for some other languages. In other words, the non-configurational structure predicts no differences in the processing of canonical and scrambled constituent orders.

In the same manner, sentences consisting of reduplicated expressions may also possess different word orders as depicted below. The following example highlights this fact with an adverb filling the $\mathrm{O}$ (object) position.

6.
a. Nangee ihi-ihi gaa andanava

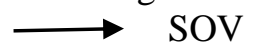
Younger sister (Nom) -ihi-ihi-noise (Adv) cry (Prog)
'Younger sister is crying with ihi-ihi noise' / 'Younger sister is sobbing'
b. Nangee andanava ihi-ihi gaa $\longrightarrow \mathrm{SVO}$

c. Ihi-ihi gaa Nangee andanava

d. Ihi-ihi gaa andanava Nangee 


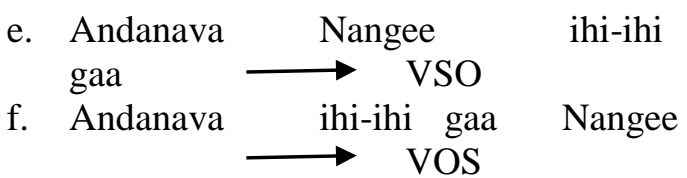

Example (6) represents a Sinhala sentence consisting of reduplicated/onomatopoeic expression ihiihi-ga (with the sound of ihi-ihi). The first sentence in (6A) represents the canonical word order as also suggested by the previous studies (Noguchi, 1984; Herath et al., 1994; Miyagishi, 2003). However, sentences from $(6 \mathrm{~B})$ to $(6 \mathrm{~F})$ represent the, the scrambled orders which also have been posited by previous studies with regard to the free-word-order phenomenon. Needless to mention that although the syntactic structures of these six word order patterns are discrepant, the basic meaning shared by all of them is; younger sister is crying (sobbing) with the sound of ihiihil (The scrambled orders may carry discoursepragmatic effects).

As shown above, if Sinhala language possesses a non-configurational structure (i.e., a flat structure) all the sentences in example (5 and 6) must consist of a structure as depicted in Figure 1.

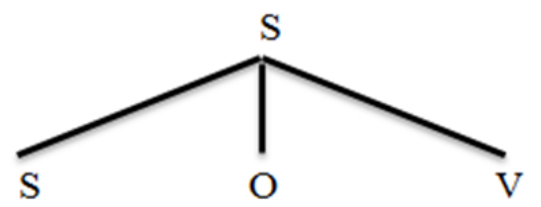

Figure 1. Flat structure in Sinhala Language

On one hand, if the syntactic structure of Sinhala sentences tends to take the structure displayed in Figure 1, it is considered that the processing of differently ordered sentences can have no difference in reaction times. In other words, all the sentences (which are differently ordered) are identical in processing. On the other hand, there are other languages that had been claimed to have a non-configurational structure due to the free-word-order phenomenon. For example, Japanese was also said to be one of them until several linguists (Hoji, 1985; Miyagawa, 1989 etc.) proved that phrasal movements result in differences in both speed and accuracy between canonical and scrambled word orders. Since then, many studies have provided evidence that although noun phrases in Japanese language seem to have a free-word order, the syntactic structure is configurational (e.g., Miyamoto and Takahashi, 2004; Tamaoka et al., 2005). Likewise, previous studies have also given evidence that some sentences in Sinhala language possess a configurational structure (Kanduboda \& Tamaoka, 2012; Tamaoka et al., 2010). For example, active sentences consisting of transitive and ditransitive verbs, passive sentences consisting of transitive verbs, are reported to have a configurational structure despite the free-word-order possibility.

\section{MATERIALS \& METHODS}

\subsection{Research Design}

The research design selected for the study was experimental in nature. Since the main task of this study was to examine whether Sinhala sentences consisting of reduplicated expressions also possess a configurational structure, this study conducted an experiment, and the following section will provide in-depth information accordingly.

\subsection{Participants}

Twenty native speakers of Sinhala (8 male and 12 female) residing in Sri Lanka participated in the following experiment. Ages ranged from 22 years and 3 months to 24 years and 4 months, with the average age being 23 years and 0 months on the day of testing. The participants were selected using the Purposive Sampling method.

\subsection{Materials}

A total of 60 stimuli were prepared for the experiment with sentences consisting of reduplicated/onomatopoeic expressions (a sample of stimuli is presented in Appendix A). 
A previous study done by (Kanduboda \& Bandara, 2014) has surveyed the acceptance of different word orders in the sentences consisting of onomatopoeic expressions, and has concluded that the SOV order is the most speedily accessed one in their mental grammars while SVO order is chosen as second most frequent amongst six word orders depicted in above examples. This study followed these results and applied SOV and SVO orders in the preparation of the stimuli for the experiment.

First, 10 sentences (for correct "yes" responses) were designed in an SOV order (Subject-ObjectVerb) with reference to the canonical order given in previous studies (Gair, 1998; Miyagishi, 2005 etc.). In order to create the scramble-ordered sentences, the SOV order was switched and SVO sentences were prepared. In this way, the SOV word order has its contrastive word order. For example, the SOV ordered sentence (7),

7. balla baw-baw-ga buranawa (Prog)

Dog (Nom) baw-baw sound (Adv) bark

The dog is barking with the baw-baw sound

was switched to SVO as (8).

8. balla buranawa baw-baw-ga

Dog (Nom) bark (Prog) baw-baw sound (Adv)

The dog is barking with the baw-baw sound

The same strategy was used to make another 20 stimuli for the correct "no" responses with either syntactically or semantically incorrect sentences. For example, the canonical noun phrase order of aliya bawbaw gaanawa, (the elephant is barking with the sound of bawbaw), is scrambled into aliya gaanwa bawbaw; thus it makes pairs of 20 correct "no" responses with canonical (10 sentences) and scrambled (10 sentences). In addition, another 20 (canonical and scrambled) controlled sentences were designed as fillers which are included in all the lists. These controlled sentences were also organized randomly, but they not used in the analysis.

If the same sentences are repeated, the reaction time is considered to become faster. Therefore, a counter-balanced design was used to assign the participants into list 1 and list 2. Each list consisted of 30 correct (15 canonical \& 15 scrambled) sentences for correct "yes" responses, 30 incorrect (15 canonical \& 15 scrambled) sentences for correct "no" responses respectively.

\subsection{Procedure}

The presentation of the stimulus was controlled by a computer program DMDX (version 5.1.0.0). Both "yes" responses, and "no" responses were presented randomly in the centre of the computer screen $600 \mathrm{~ms}$ after the appearance of a line of asterisks '******' at the eye fixation point on the screen. That is, after $600 \mathrm{~ms}$, the sentence disappeared and the participants were asked to record their judgment. However, prior to the experiment, all the participants were instructed to respond (press "yes" or "no" keys for the answers) as quickly and as accurately as possible to the sentences appeared on the computer screen. In advance to the actual experiment, all the participants were trained and acknowledged regarding the procedure of the experiment with necessary detailed information.

\section{RESULTS}

Extremes among sentence correctness decision times (less than 500 milliseconds and longer than 5,000 milliseconds.) were recorded as missing values. Table 1 illustrates the means and standard deviations of correct 'Yes' and 'No' reaction times and error rates for sentence correctness decisions. Outliers were treated as follows: Before performing the analysis, reaction times outside of 2.5 standard deviations 
at both the high and low ranges were replaced by boundaries indicated by 2.5 standard deviations from the individual means of participants in each category. In the statistical tests, $\left(F_{1}\right)$ represents the subject variability. In addition, only stimulus items of correct "Yes" responses were used in the analyses of reaction times.

Table 1. Reaction Times and Error Rates in Onomatopoeic Expression

\begin{tabular}{cccccccc}
\hline \multirow{2}{*}{$\begin{array}{c}\text { Response } \\
\text { Type }\end{array}$} & Sentence & \multicolumn{2}{c}{ Reaction Time (ms) } & & \multicolumn{2}{c}{ Error Rate (\%) } \\
\cline { 7 - 8 } \cline { 7 - 8 } & Type & $\mathrm{M}$ & SD & & M & SD \\
\hline 'Yes' & SOV & 1112 & 166 & & $0.40 \%$ & $0.16 \%$ \\
Responses & SVO & 1327 & 173 & & $0.79 \%$ & $0.16 \%$ \\
\hline Scrambling Effects & & 215 & & & & \\
No' & SOV & 1217 & 182 & & $0.62 \%$ & $0.28 \%$ \\
Responses & SVO & 1325 & 102 & & $0.82 \%$ & $0.12 \%$ \\
\hline
\end{tabular}

A series of one-way analyses of variance (ANOVAs) with repeated measures in canonical and scrambled noun phrase order were conducted on reaction times (milliseconds) and error rates (percentages), using subject variability $\left(F_{1}\right)$. Results for correct "yes" responses indicated that SOV ordered sentences had shorter reaction times $\left[F_{l}(1,19)=24.059, \mathrm{p}\right.$ $<.001]$, and lower error rates $\left[F_{1}(1,19)=5.765\right.$, $\mathrm{p}<.05]$ than the same sentences in scrambled order. Correct "no" responses also displayed the same results: canonical order showed shorter reaction times $\left[F_{l}(1,19)=76.232, \mathrm{p}<.001\right]$, and lower error rates $\left[F_{l}(1,19)=8.061, \mathrm{p}<.01\right]$. SO, this implies that participants were sensitive to different word orders because they had to make a conscious effort to process those whereas the canonical word order is a better reflection of their I-language.

Overall, both "yes" responses and "no" responses resulted with scrambling effects (difference in reaction times between SOV ordered sentences and SVO ordered sentences) as shown in Table 1 (215 milliseconds difference). These results suggest two aspects about the sentences examined in this study; first, sentences consisting of reduplicated (onomatopoeic) expressions also possess a configurational structure, and second, since the SOV ordered sentences were processed faster than the SVO ordered sentences, the canonical Subject-Object-Verb order remains unchanged as proposed in the present study.

\section{DISCUSSION}

This study was conducted to examine whether Sinhala sentences consisting of reduplicated (onomatopoeic) expressions also possess a configurational structure. Although some previous studies (Inman, 1993; Gair, 1998) have proposed that the syntactic structure in Sinhala language possesses a non-configurational structure, some other previous studies in experimental linguistics (Ananda, 2011; Hettiarachchi, 2015; Kariyakarawana, 1998; Kanduboda \& Tamaoka, 2012; Tamaoka et al., 2012) have provided evidence on the configurational structure in Sinhala language with respect to many sentence types. However, sentences consisting of reduplicated (onomatopoeic) expressions have not been examined in the previous studies with respect to the configurational structure. Therefore, this study conducted an experiment to examine the configurational structure in the sentences consisting of reduplicated (onomatopoeic) expressions.

The experiment was organized with different sentence types for correct "yes" and correct "no" responses. A counter-balanced design was applied in order to prevent reaction times becoming faster due to repeated stimuli. The results were significantly different in reaction times between the SOV ordered sentences and SVO ordered sentences. This is evident for the configurational structure in the sentences consisting of reduplicated (onomatopoeic) expressions. Thus, as with other previous studies (Kanduboda, 2011; Kanduboda \& Tamaoka, 2012; Tamaoka et al., 2012), this study confirms the observation that sentences with reduplicated expressions in Sinhala language in the canonical word order could be processed faster than those with different word orders, and therefore should be considered as evidence for configurational nature of the language. 


\section{CONCLUSION}

The intended goal of this study was to examine whether sentences in the canonical word order containing re-duplicated expressions could be processed faster than those with different word orders, and therefore to what extent such orders form an integral part of one's mental grammar, the I-language (Chomsky, 1986). And based on this, a further observation could be made about configurationality of the language. The results of this study confirm that the syntactic structure in Sinhala is indeed configurational in terms of processing speed. Further, the hypothesis that the canonical word order is very much a part of one's mental grammar in contrast to conscious effort-making with respect to other word orders holds true as the SOV / canonical order sentences were processed faster during the experiment. However, the results of this study cannot withstand for some other questions that can be raised. For example, there are other types of sentences such as sentences consisting of adverbials, adjective modifiers expressions that should be taken into account and examined in detail. These can be explored in future research.

\section{REFERENCES}

ANANDA L. The Focus Construction in Sinhala. Germany: Lap Lambert Publishing; 2011.

BAYER J \& KORNFILT J. Against scrambling as an instance of Move-alpha. In: N. Cover and H. van Riemsdijk, editors. Studies on Scrambling: Movement and non-movement approaches to free-word-order phenomena. Berlin: Mouton de Gruyter. 1994; 17-60.

BOŠKOVIĆ Z \& TAKAHASHI D. Scrambling and last resort. Linguistic Inquiry. 1988; 29:347366.

BOŠKOVIĆ Z. Topicalization, focalization, lexical insertion, and scrambling. Linguistic Inquiry. 2004; 35(4): 613-638.
BRESNAN J. Lexical functional syntax. Cambridge, MA: Blackwell. 2001.

CHANDRALAL D. Sinhala. Amsterdam: John Benjamins Publishing Compnay. 2010.

CHOMSKY N. On Wh-movement. In: Culicover P, Wasow T and Akmajian A, editors. Formal Syntax. New York: Academic Press. 1977; 71-155.

CHOMSKY N. Knowledge of language; its nature, origin and use. New York: Praeger. 1986.

DANIELA I \& CHARLES R. I-Language: an introduction to Linguistics as cognitive science. New York: Oxford. 2008.

ENGLEBRETSON R \& CAROL G. editors. Santa Barbara papers in linguistics: proceeding from the workshop on Sinhala linguistics. Santa Barbara, CA: Department of Linguistics at the University of California, Santa Barbara. 2005.

E KISS K. Scrambling as the base generation of random complement order. In: Corver $\mathrm{N}$, and $\mathrm{H}$. van Riemsdijk, editors. Studies on scrambling. Movement and non-movement approaches to free-word-order phenomena. Berlin: Mouton de Gruyter. 1994; 221-56.

FARMER A. On the interaction of morphology and syntax. Unpublished doctoral dissertation, Massachusetts Institute of Technology, Cambridge. 1980.

GAIR W JAMES. Syntax: Configuration, Order, and Grammatical Function. In: Lust, C. Barbara editors. Studies in South Asian Linguistics; Sinhala and Other South Asian Languages. Oxford University Press, New York. 1998; 47-110.

HAIDER H. $\theta$-tracking systems: Evidence from German. In: Maracz L, and Muysken P, editors. Configurationality. Dordrecht: Foris. 1988; 185-206. 
HALE K. Remarks on Japanese Phrase Structure: Comments on the papers on Japanese Syntax. MIT Working Papers in Linguistics. 1980; 2: 185-203.

HENADEERAGE DK. Topics in Sinhala Syntax. Unpublished Doctoral Dissertation. The Australian National University. 2002.

HERATH A, HYODO Y, KAWADA Y, IKEDA T \& HEARTH S. A Practical Machine Translation System from Japanese to Modern Sinhalese, Gifu University; 1994. 153-162.

HETTIARACHCHI S. Sinhala Object Scrambling Revisited. In: Proceedings from the Pennsylvania Lingustics Conference 39, University of Pennsylvania Working Papers in Linguistics. 2015; 21(1): article 13.

HOJI H. Logical Form Constraints and Configurational Structure in Japanese. Ph.D. dissertation, University of Washington, Seattle. 1985.

INMAN MV. Semantics and pragmatics of colloquial Sinhala involitive verbs. Doctoral dissertation, Stanford University. 1994.

KANDUBODA APB \& BANDARA N. A Usage Based Research on Sinhala Onomatopoeia- Focusing on Semantic, Morphological, and Syntactic aspects. International Research Conference on Humanities and Social Sciences, Faculty of Humanities and Social Sciences, University of Sri Jayewardenepura, Sri Lanka. 2014.

KANDUBODA APB. Issues in Sinhalese Syntax- Sentence Processing and Word Order. The Sri Lanka Journal of the Humanities, University of Peradeniya, Sri Lanka. 2011; 37: 159-170.

KANDUBODA APB \& TAMAOKA K. Priority Information Determining the Canonical Word Order of Written Sinhalese Sentences. Open Journal of Modern Linguistics; 2012. 2, 26-33.
MIYAGAWA S. Structure and Case Marking in Japanese. Syntax and Semantics. Vol. 22 San Diego, CA: Academic Press. 1989.

MIYAGISHI T. A Comparison of Word Order between Japanese and Sinhalese In: Bulletin of Japanese Language and Literature, Yasuda Women's University. 2003; 33.

MIYAMOTO ET \& TAKAHASHI S. Filler-gap dependencies in the processing of scrambling in Japanese. In: Language and Linguistics. 2004; 5: 153-166.

MOHANAN T. Arguments in Hindi. Unpublished doctoral dissertation. Stanford University, Stanford. 1990.

NEELEMAN A. Scrambling as a D-structure phenomenon. In: Corver $\mathrm{N}$, and $\mathrm{H}$. van Riemsdijk, editors. Studies on Scrambling. Movement and non-movement approaches to free-word-order phenomena. Berlin: Mouton de Gruyter. 1994; 387-429.

NOGUCHI T. Shinhara-go nyuumo. Tokyo: Daigaku Shorin. 1984.

ROSS J. Constraints on variables in syntax. Unpublished doctoral dissertation, Massachusetts Institute of Technology, Cambridge. 1967.

SAITO M \& HOJI H. Weak crossover and move $\alpha$ in Japanese. Natural Language and Linguistic Theory. 1983; 1: 245-59.

SAITO M. Some asymmetries in Japanese and their theoretical implications. MIT Dissertation. Cambridge, MA: MITWPL. 1985.

TAMAOKA K, SAKAI H, KAWAHARA J, MIYAOKA Y, LIM H \& KOIZUMI M. Priority information used for the processing of Japanese sentences: In: Thematic roles, case particles or grammatical functions. Journal of Psycholinguistic Research. 2005; 34: 273-324. 
TAMAOKA K, KANDUBODA ABP \& SAKAI H. Effects of word order alternation in the processing of spoken Sinhalese sentences. In: Proceedings of $140^{\text {th }}$ conference by the linguistic society, Japan. 2010; 32-37.

\section{APPENDIX A}

A sample of stimuli for correct "yes" responses in SOV order

1. Aiya gudu-gudu-ga wathura

bonava

Elder brother gudu-gudu-noise water drink 'Elder brother is drinking water with the noise gudu-gudu'

2. Balla baw-baw-ga buranava

Dog baw-baw-noise bark

'The dog is barking with the noise baw-baw'

3. Nangi ihi-ihi-ga andanava

Younger sister ihi-ihi-noise cry

'Younger sister is crying with the noise ihiihi'

4. Lamaya baka-baka-ga hinawenava Child baka-baka-noise laugh

'The child is laughing with baka-baka noise'

5. Lamaya chau-chau-ga bath kanava

Child chau-chau-noise rice eat

'The child is eating rice with the noise chauchau'

6. Malli dung-dung-ga bera gasai

Younger brother dung-dung-noise drumbeat

'Younger child is beating drums with the noise dung-dung'

7. Akka hiki-hiki-ga sinasuna

Elder sister hiki-hiki noise laughed

'Elder sister laughed with hiki-hiki noise'

8. Balla sata-sata-ga nakuta wananava

Dog sata-sata noise tail wag

'The dog is wagging its tail with sata-sata noise' 